Volume 3, Issue 1, pages 35-54

p-ISSN 2655-8564, e-ISSN 2685-9432

\title{
IoT Based Smart Classroom
}

\author{
Prajas Kadepurkar ${ }^{1}$, Prim Dsouza ${ }^{1, *}$, Nivya Jomichan ${ }^{1}$ \\ ${ }^{1}$ Department of Computer Engineering, \\ Xavier Institute of Engineering, Mahim, Mumbai, Maharashtra, India \\ ${ }^{*}$ Corresponding Author: prim.prd@gmail.com
}

(Received 22-07-2020; Revised 09-08-2020; Accepted 23-08-2020)

\begin{abstract}
A classroom is a place where there is always room for development; therefore just as the development for a student results in the ease of living, similarly a smart classroom focuses on the structural development leading to effective time and energy utilization. This project offers three major upgradation in classroom; the first being able to book a classroom dynamically using Raspberry $\mathrm{Pi}$ and toggling lights and fans using NodeMCU and a mobile application which also helps notify a student about the subject of the lecture, the time and the venue related to the commencement of a period. The second section of this project inputs the attendance of a student check in, using a portable real-time biometric system whose data can further be used to calculate the attendance statistics of each student which can be viewed by the respective student or the teachers can keep a track on their own assigned class using the mobile application. And the last part of the project focuses on keeping track of all the lights and fans, which are on after the lecture. After the lecture is done, it will check the status of the room, whether some other teacher for some other subject is using the lecture hall. Also when the teacher ends the class, the lights and fans will be switched off after 5 minutes buffer provided for the students to
\end{abstract}




\section{International Journal of Applied Sciences and Smart Technologies}

Volume 3, Issue 1, pages 35-54

p-ISSN 2655-8564, e-ISSN 2685-9432

checkout. It will wait for 15 minutes and if it still does not receive any request then it will switch off the lights and fans of that particular lecture hall.

Keywords: Raspberry Pi, NodeMCU, portable, real-time biometric system

\section{Introduction}

In most of the Colleges and Universities, we have witnessed scenarios where the lights and fans of a classroom are turned on even if there is no person in the class or a similar scenario where a small group of people are sitting in one corner of a classroom where the lights and the fans in the whole classroom are switched on. These scenarios account to a great deal of electricity wastage. As mentioned in [1], without adequate electricity, it becomes challenging for a person towards concentrating on their professional work or study and hence, current scenario insist towards highly efficient and effective usage of any form of power in educational institutes. Suppose the working hour of an institution is 7 hours, let us assume that the lights and fans are switched on for most of it. This implies that a total of $4830 \mathrm{~W}$ is being consumed in 7 hours. This means that the institution consumes $1110.9 \mathrm{~kW}$ per month whereas, with a smarter system it can be reduced to $634.8 \mathrm{~kW}$ per month (Detailed calculation shown further under Results). The traditional attendance system in an educational institute makes the teacher shouts out the roll numbers in the class and mark the attendance of a student on a paper upon acknowledgement of the student. This system proves to be inefficient in a lot of ways. Firstly, calling out the roll numbers in front of a class is labor expensive. Secondly, marking the attendance on a paper wastes a lot of paper and losing this piece of paper essentially means there is no record of the student's attendance. Consider 10 subjects per year; 4 attendance sheet per class per academic year, i.e. 40 sheets per year per class. Let's say there are 12 classes in a given institution, this implies that with a smarter system we can save 480 sheets per year. Lastly, a student can fraudulently acknowledge for a student not present in the class. In essence, the traditional way of marking attendance can prove to be inefficient in terms of labor work, time, paper and security. Considering the above two scenarios, we developed a system where one part of 


\section{International Journal of Applied Sciences and Smart Technologies}

Volume 3, Issue 1, pages 35-54

p-ISSN 2655-8564, e-ISSN 2685-9432

the system focuses on automated control over the electrical components in a classroom where these components of a particular classroom or lecture hall will be turned on only when a lecture is taking place in the aforementioned classroom or lecture hall which helps in saving power. This solves one of the two previously mentioned problems. The second part of our system helps reduce the difficulties encountered in the traditional attendance system. In this portable attendance system, attendance of a student is marked using a biometric sensor that prevents fraudulent entries and saves labor work. Further, the records are stored into a database, which reduces the risk of losing the records. Also, the system being portable can be circulated among the students as the lecture is taking place that helps in saving time required after the teaching session as in traditional attendance system.

\section{Literature Survey}

In this section we elaborate the automatic lighting and control system for classroom, a classroom scheduling service for smart classes, design and development of portable classroom attendance system based on arduino and fingerprint biometric, web-based student attendance system using RFID technology.

\subsection{Automatic Lighting and Control System for Classroom.}

Current scenario insists towards highly efficient and effective usage of any form of power in educational institutions like Colleges and universities where we use power for our teaching in classroom or labs. It is common practice that most of us leave the classrooms or labs with Air conditioner, Fan and lighting on even if no students or Faculty members present. These amount to unnecessary wastage of power, contributing to country's energy resource. So accordingly, an automatic lighting and control using Arduino for the efficient use of energy in Classroom condition where we have divided the classroom intro grids has been developed. The system developed will control lighting in a particular area of classroom based on the presence of human using relay control compared to the one placed in ceiling which would switch on or off based on presence of human in room irrespective of position. In addition to relay control, we have 


\section{International Journal of Applied Sciences and Smart Technologies}

Volume 3, Issue 1, pages 35-54

p-ISSN 2655-8564, e-ISSN 2685-9432

also provided mobility and remote command execution to system using Android mobile App via Bluetooth to control lighting based on voice command [1].

\subsection{A Classroom Scheduling Service for Smart Classes.}

A typical case study demonstrates that SmartClass provides a new efficient paradigm to the traditional classroom scheduling problem, which could achieve high flexibility by software services reuse and ease the burden of educational programmers. Evaluation results on efficiency, overheads and scheduling performance demonstrate the SmartClass has lower scheduling over heads with higher efficiency [2].

\subsection{Design and Development of Portable Classroom Attendance System based on Arduino and Fingerprint Biometric.}

The objective of this paper is to design and develop a portable student attendance system used in educational institutions as well as to design a user friendly attendance mechanism especially for the lecturer which incorporates security criteria for the stored data. The design and development of a portable classroom attendance system based on fingerprint biometric is presented. This paper introduces a portable fingerprint based biometric attendance system which addresses the weaknesses of the existing paper based attendance method or long time queuing. The system helped to reduce many issues such as, denying the possibilities of cheating in recording the attendance, helps to ease the lecturers to keep track of students attendance, the encryption technique adds more security so there will be no anonymous fingerprint which is able to tamper with the recorded data, and the portability saves time in taking attendance instead of queuing in a line [3].

\subsection{Web-based Student Attendance System using RFID Technology}

The existing conventional attendance system requires students to manually sign the attendance sheet every time they attend a class. As common as it seems, such system lacks of automation, where a number of problems may arise. This include the time unnecessarily consumed by the students to find and sign their name on the attendance sheet, some students may mistakenly or purposely signed another student's name and 


\section{International Journal of Applied Sciences and Smart Technologies}

Volume 3, Issue 1, pages 35-54

p-ISSN 2655-8564, e-ISSN 2685-9432

the attendance sheet may got lost. Having a system that can automatically capture student's attendance by flashing their student card at the RFID reader can really save all the mentioned troubles. The main idea behind the system is to capture student attendance in a semi-automated way where the students are required to flash their student card at the RFID reader upon entering the classroom. This way, the student ID is instantly captured by the reader, after which the data is sent to the online server for recording purpose [4].

The aforementioned papers have been taken as a reference and a guide for our project as a collective idea consisting each feature presented by the individual papers. As presented in the paper on Automatic light and control system for classroom [1], our IoT Based smart classroom has a system which would switch on or off the lights and fans of a classroom based on the lecture status as and when initiated by a lecturer. Using the mobile application, the lecturer decides the class and lecture to be conducted and the lights and fans will be switched on if the class has started and switches off automatically when the lecturer ends the class. All the students are also notified regarding the lecture status, using the web application. This leads us to the need of smart class scheduling system to avoid collision and chaos. As highlighted in the paper on A Classroom Scheduling Service for Smart Classes [2], the issues concerning classroom scheduling are vital and our system ensures minimal collisions. The lecturer can only select from a set of available lecture halls for them to initiate a notification regarding their lecture. Such measures lead to a more dynamic and more convenient scheduling methodology. The IoT based smart classroom provides the main functionality of integrating intelligent toggling of the physical electrical aspects of a class along with a portable biometric attendance system on a dynamically scheduled lecture hall. As mentioned in the paper on Web-based Student Attendance System using RFID Technology [4], a more secure, efficient way than a pen and paper system for attendance is using technology to do the required work than humans, but as present in this paper, the use of RFID has many drawbacks, some of them including false entry or non-portability in terms of scanning for attendance, which is why our project uses a fingerprint sensor as used in the paper on Design and Development of Portable Classroom Attendance System based on 


\section{International Journal of Applied Sciences and Smart Technologies}

Volume 3, Issue 1, pages 35-54

p-ISSN 2655-8564, e-ISSN 2685-9432

Arduino and Fingerprint Biometric [3], but rather making it portable using a raspberry $\mathrm{Pi}$, such that it can be circulated in the lecture hall. In our research, enhancements have been made in terms of security, cost, and performance, therefore making a classroom smart as the project suggests. In this project we are making use of NodeMCU Microcontroller board, which consist of ESP8266 Wi-Fi enabled chip and Raspberry Pi single board computer.

\section{System Design}

The IoT based smart classroom provides the main functionality of integrating intelligent toggling of the physical electrical aspects of a class along with a portable biometric attendance system on a dynamically scheduled lecture hall. In this project we are making use of NodeMCU Microcontroller board, which consist of ESP8266 Wi-Fi enabled chip and Raspberry Pi which is a single board computer.

\subsection{Hardware Processing Unit}

The Hardware Processing Unit is further divided into two major subunits. First subunit focuses on controlling the electrical components of the classroom and the second subunit is used for marking student attendance. The attendance handling subunit uses NodeMCU Development Board / kit v1.0 (Version 2) microcontroller whereas the electricity handling subunit use Raspberry Pi Single Board Computer. The NodeMCU microcontrollers act as a client to the local server which is described further. The Raspberry Pi acts as an admin to the Firebase Server and can directly communicate with the database. 
Volume 3, Issue 1, pages 35-54

p-ISSN 2655-8564, e-ISSN 2685-9432

\subsubsection{Electricity Handling Unit}

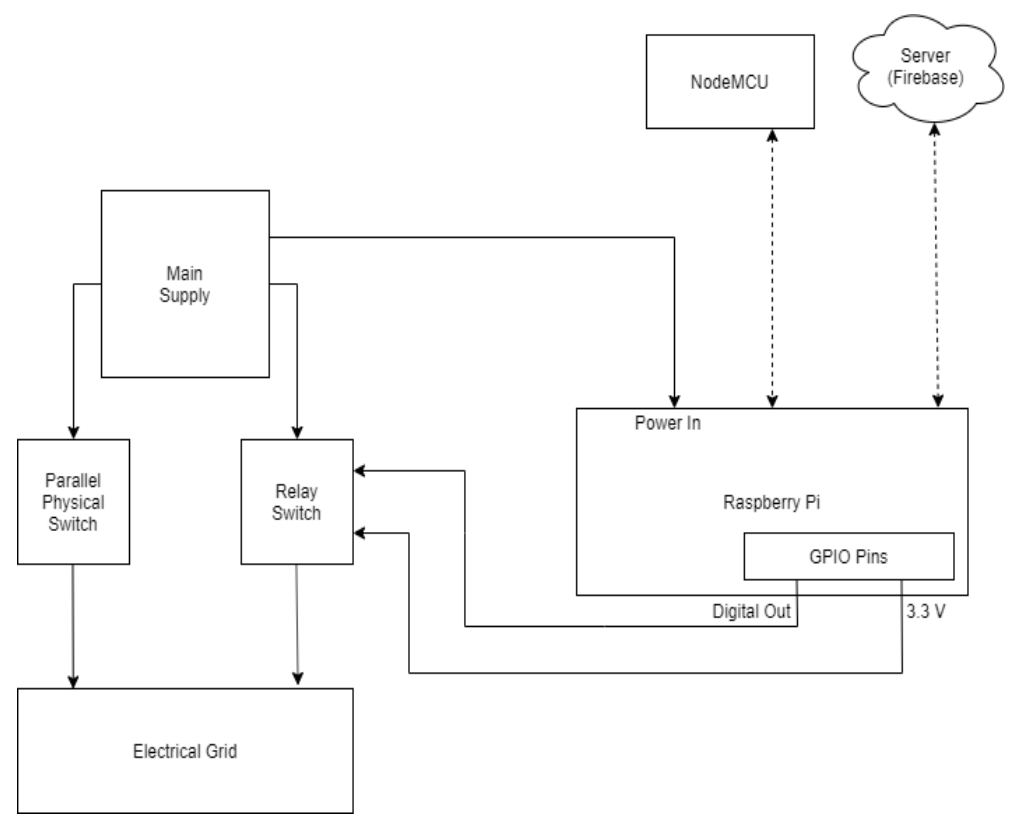

Figure 1. Block diagram of electricity handling subunit

Figure 1 shows the block diagram for the working of Electricity Handling unit. Each lecture hall will contain its own electrical processing unit with a unique ID assigned to it. A parallel physical switch is provided to the electricity grid to manually control the switches as well. When the teacher starts or ends a lecture, the Pi toggles the relay switch and controls the electricity grid. The Raspberry Pi is provided with an external power supply. Along with the handling of electricity of the particular lecture hall, the Raspberry Pi also updates its local file and the database according to the attendance marked. The server in turn, also keeps validating the data on the database with the local file (.json extension) and updates it's contents. 


\section{International Journal of Applied Sciences and Smart Technologies}

Volume 3, Issue 1, pages 35-54

p-ISSN 2655-8564, e-ISSN 2685-9432

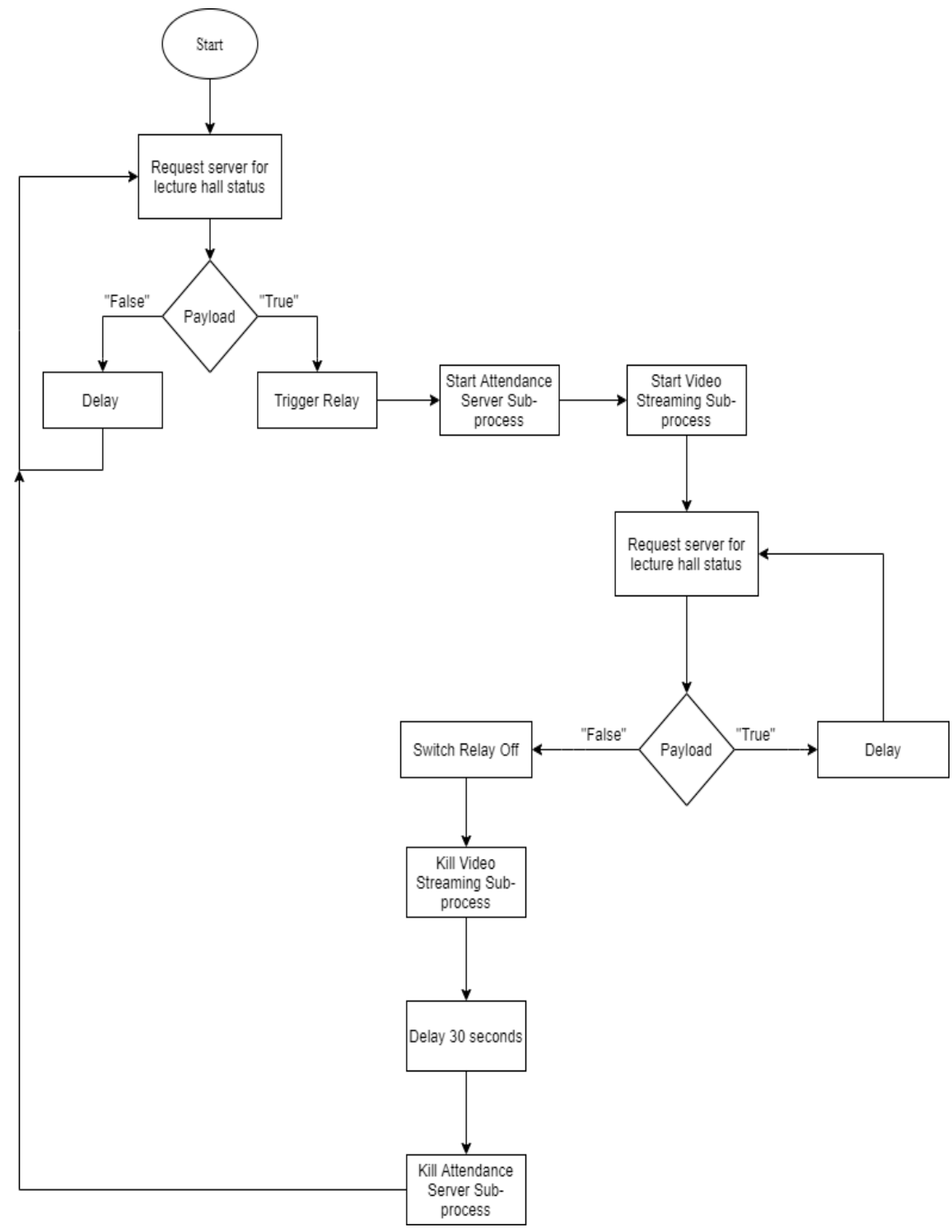

Figure 2. Flowchart of electricity handling subunit

A relay is an electrically controlled electromagnetic switch. It can be controlled with low level voltages like 5V from Raspberry Pi GPIOs or 3.3V from NodeMCU pins. Their main use is controlling circuits by a low power signal or when several circuits must be controlled by one signal. The input to a relay consists of $\mathrm{VCC}$, usually $5 \mathrm{~V}$ or 3.3V in some cases, GND normally connected to negative supply, and INn pins where $\mathrm{n}$ is the number of channels the relay consists. The output consists of three pins which provide 2 different configurations to control circuits. One of the output pins is COM which is the common pin. The other two output pins are NO which stands for Normally 


\section{International Journal of Applied Sciences and Smart Technologies}

Volume 3, Issue 1, pages 35-54

p-ISSN 2655-8564, e-ISSN 2685-9432

Open and keeps the circuit open before the relay is triggered and NC which stands for Normally Closed which keeps the circuit closed before the relay is triggered. The flowchart of electricity handling subunit is shown in Figure 2, and a two channel relay module is illustrated in Figure 3.

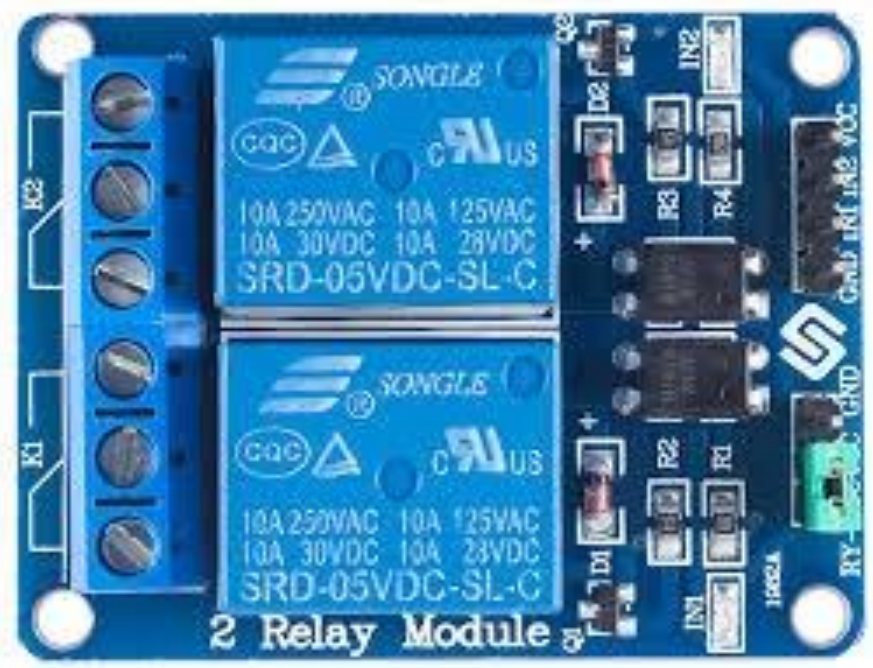

Figure 3. Two channel relay module [5]

\subsubsection{Attendance Handling Unit}

Here we describe our Attendance Handling Unit. This includes Block diagram of attendance processing subunit, flowchart of attendance processing subunit, etc.

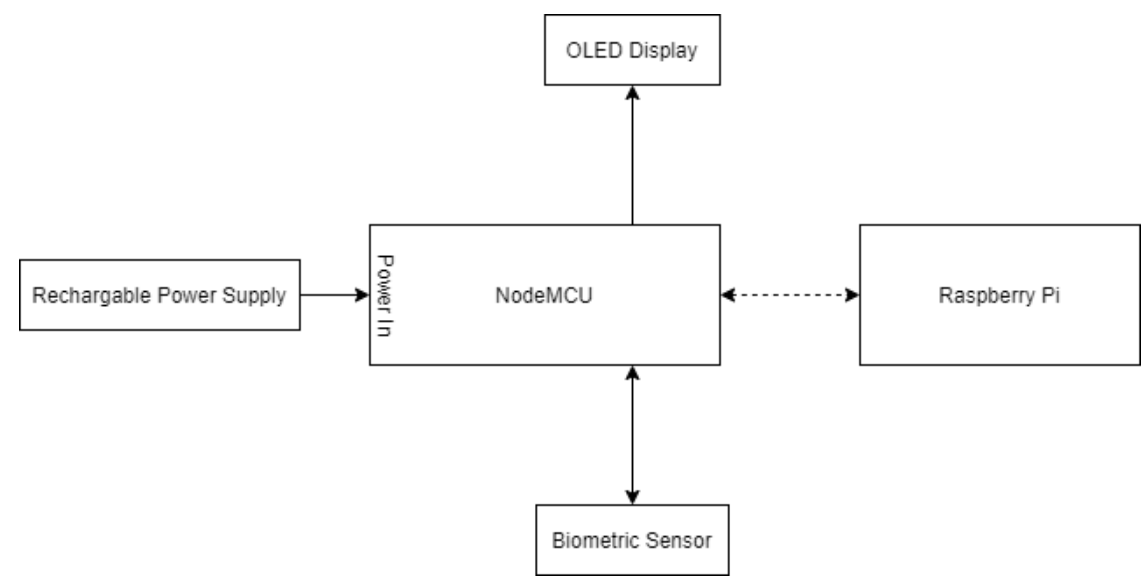

Figure 4. Block diagram of attendance processing subunit 


\section{International Journal of Applied Sciences and Smart Technologies}

Volume 3, Issue 1, pages 35-54

p-ISSN 2655-8564, e-ISSN 2685-9432

Figure 4 shows the block diagram for Attendance Processing system which uses a biometric sensor to verify each registered student's fingerprint with its respective ID and sends it to the Raspberry Pi to update in the local file and the database. The OLED screen displays the information of the student once his/her attendance is marked. NodeMCU is provided with a rechargeable power supply.

When the device is circulated amongst the students, each student scans his / her fingerprint on the system. This fingerprint is then matched with database stored on the sensor. In reference to the matched ID, a local JSON file is updated to mark the respective student as present and the matched ID is sent wirelessly to the server. The name of the student, depending upon the ID matched, is then displayed on the screen which acts as a validation for the student that his / her attendance has been recorded. The screen displays the message 'Try Again' if something goes wrong. Figure 5 shows a flowchart of attendance processing subunit. Figures 6 and 7 depicts R307 optical fingerprint scanner [6] and R307 optical fingerprint scanner [7], respectively. 
International Journal of Applied Sciences and Smart Technologies

Volume 3, Issue 1, pages 35-54

p-ISSN 2655-8564, e-ISSN 2685-9432

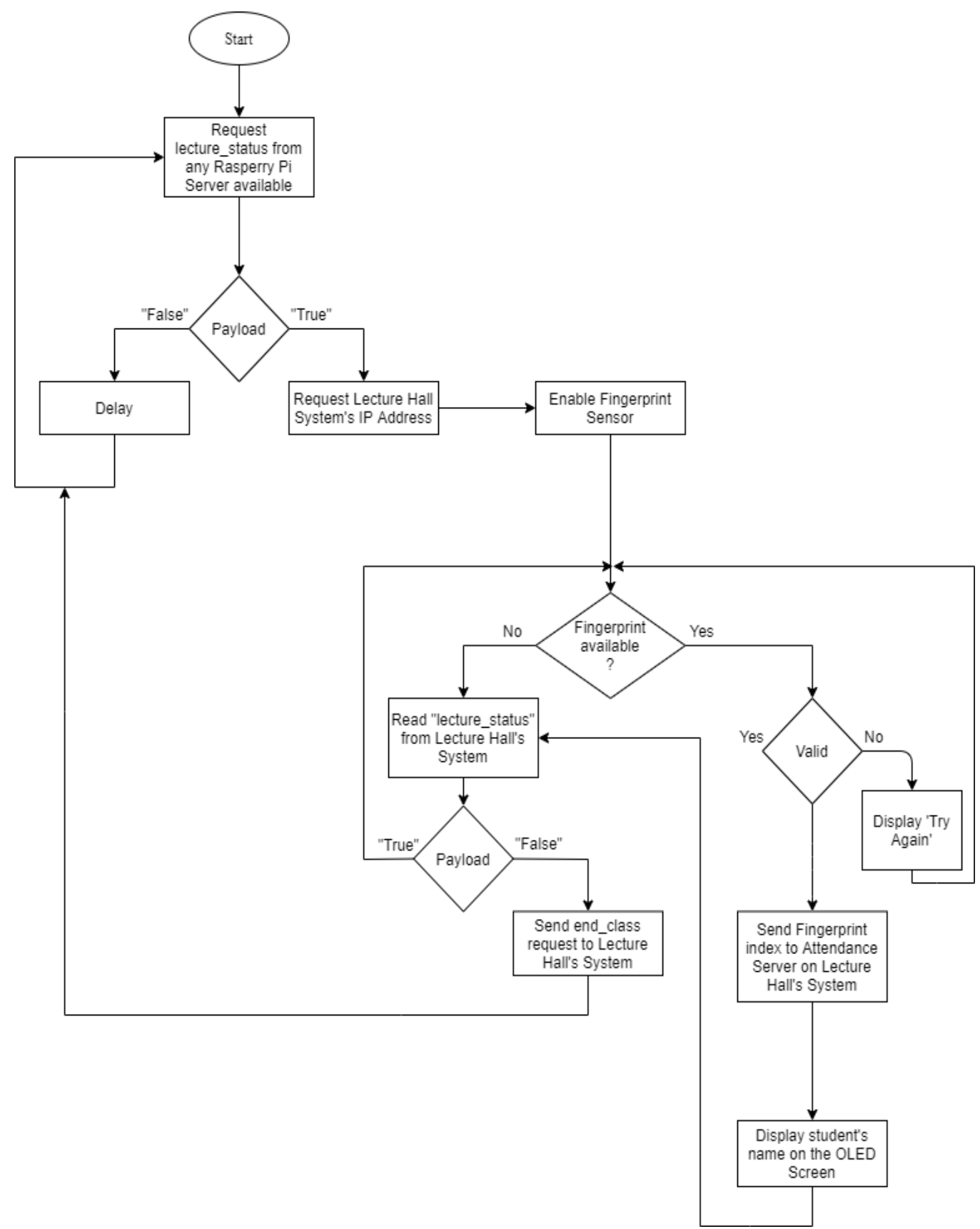

Figure 5. Flowchart of attendance processing subunit 
International Journal of Applied Sciences and Smart Technologies

Volume 3, Issue 1, pages 35-54

p-ISSN 2655-8564, e-ISSN 2685-9432

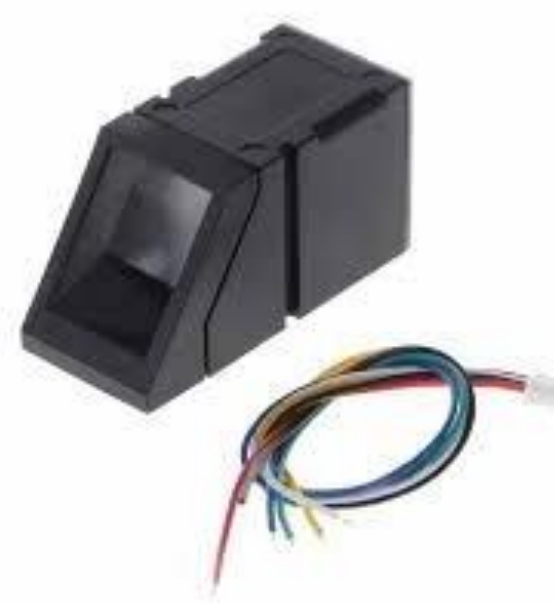

Figure 6. R307 optical fingerprint scanner [6]

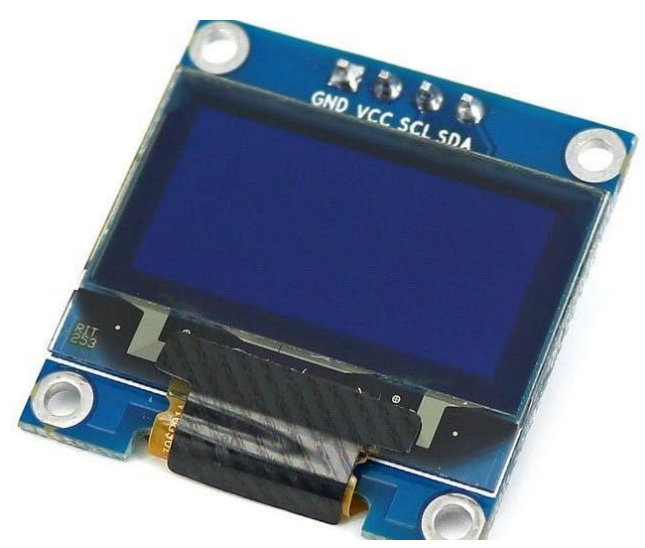

Figure 7. R307 optical fingerprint scanner [7]

Figure 8 shows the flowchart of the Attendance Server which runs on Raspberry Pi which keeps on checking for incoming requests and updates the database accordingly. 


\section{International Journal of Applied Sciences and Smart Technologies}

Volume 3, Issue 1, pages 35-54

p-ISSN 2655-8564, e-ISSN 2685-9432

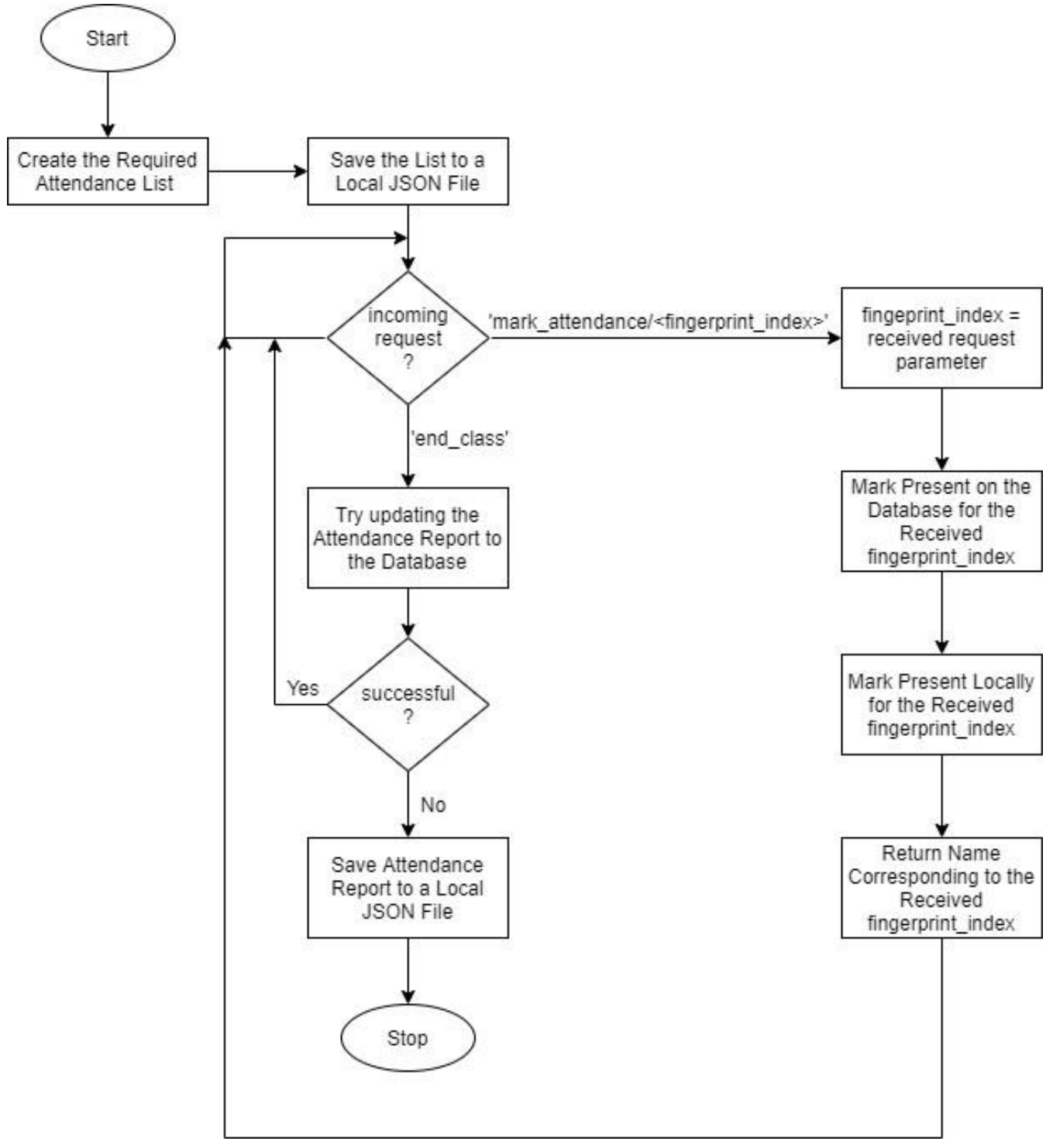

Figure 8. Flowchart of attendance server on Raspberry Pi

\subsection{Software Processing Unit}

The software processing unit consists of a cross platform native mobile application. The application is developed using Flutter SDK for Dart programming language developed by Google. Flutter enables the development of cross platform mobile applications i.e. Android and iOS from a single codebase. It means that we only have to write a single piece of that, which further will be converted to native machine languages by the Flutter SDK, to work on both the platforms. 


\section{International Journal of Applied Sciences and Smart Technologies}

Volume 3, Issue 1, pages 35-54

p-ISSN 2655-8564, e-ISSN 2685-9432

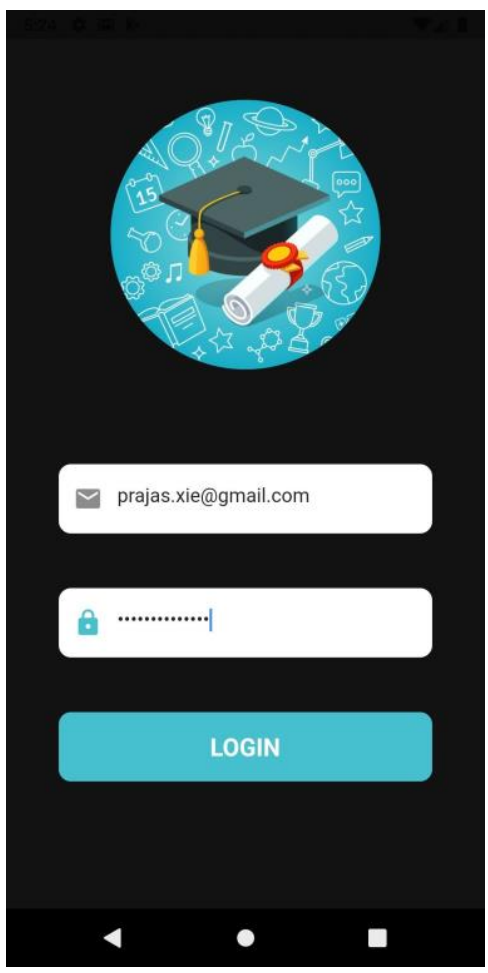

Figure 9. Mobile application login screen

The above mentioned application is a role based application which consists of the following two roles:

\subsubsection{Professor}

A professor after logging in, can select the class and a lecture hall, given the status of both is free, to start the lecture. The above mentioned professor can also view the attendance statistics of a particular class in the application. The professor can view the list of students who are defaulters subject wise and the Class teacher can see the defaulter list of the whole class with all the subjects. 
International Journal of Applied Sciences and Smart Technologies

Volume 3, Issue 1, pages 35-54

p-ISSN 2655-8564, e-ISSN 2685-9432
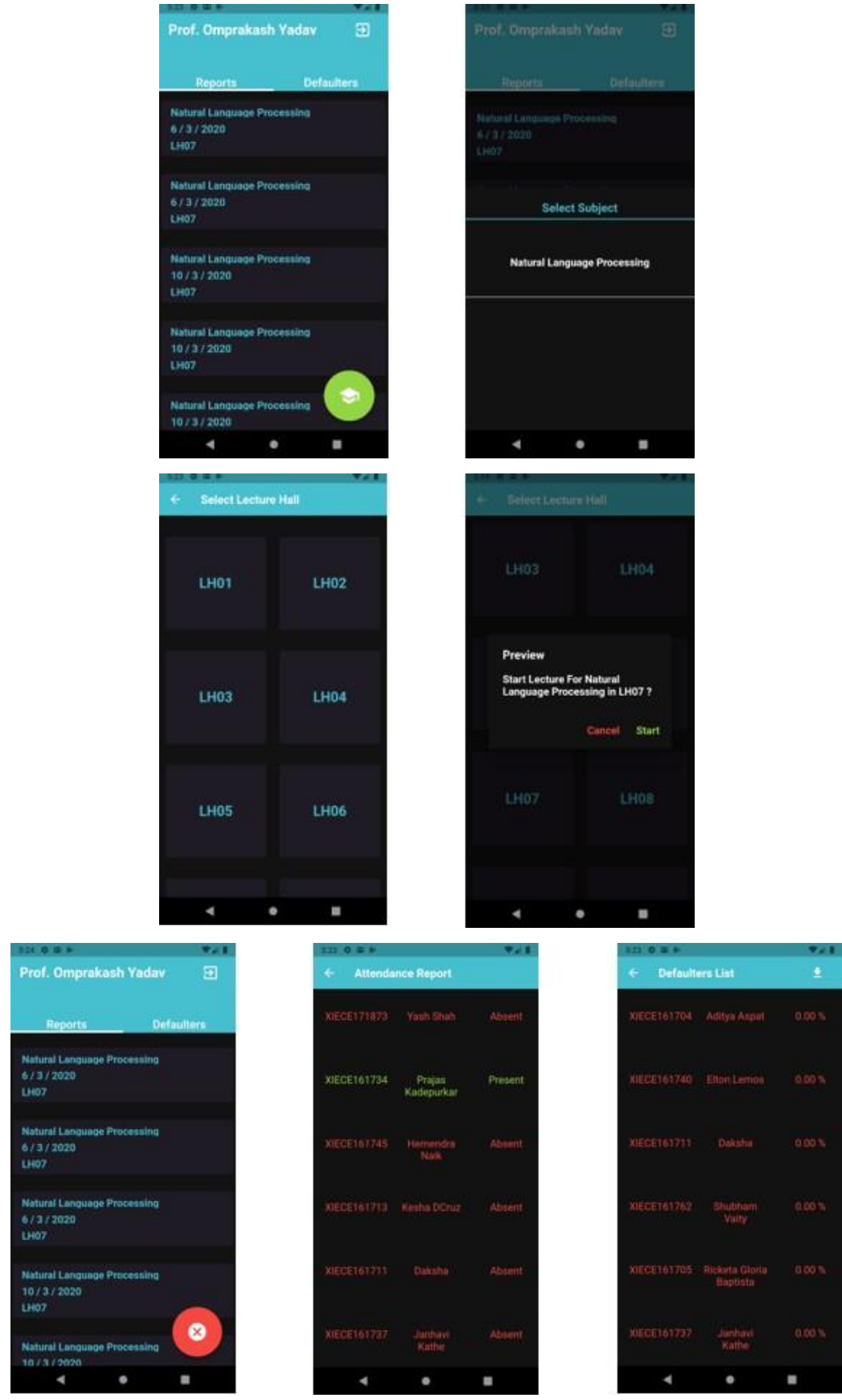

Figure 10. Professor's mobile application interface 


\section{International Journal of Applied Sciences and Smart Technologies}

Volume 3, Issue 1, pages 35-54

p-ISSN 2655-8564, e-ISSN 2685-9432

\subsubsection{Student}

As a student, the user can login to the application by entering his / her credentials. When the professor starts the lecture, each registered student is notified about the details of the lecture to be conducted. After logging in, the user can view his / her attendance statistics for each class he has registered for.

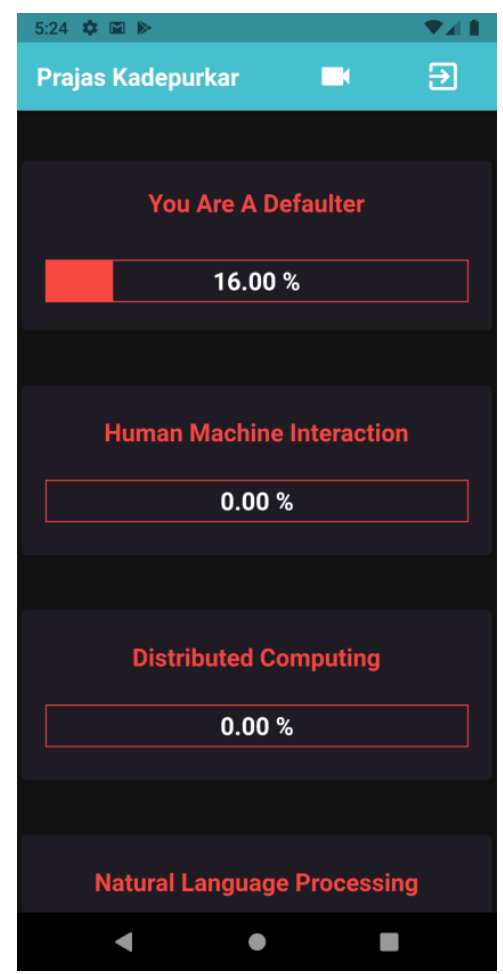

Figure 11. Student's mobile application interface

\section{Results}

The user interface is shown in Figure 9,10 and 11. The registered professors and students can successfully $\log$ in to their accounts. Professors are able to select the classroom, the subject and the batch of student registered for the given course, he or she may start or end the lecture and view the overall attendance of the students and the defaulter list for the class they teach. Class teachers can also view the attendance of the entire class for all the courses the students have enrolled for. Professors can also download the attendance statistical list as a csv file as shown in Figure 12. 


\section{International Journal of Applied Sciences and Smart Technologies}

Volume 3, Issue 1, pages 35-54

p-ISSN 2655-8564, e-ISSN 2685-9432

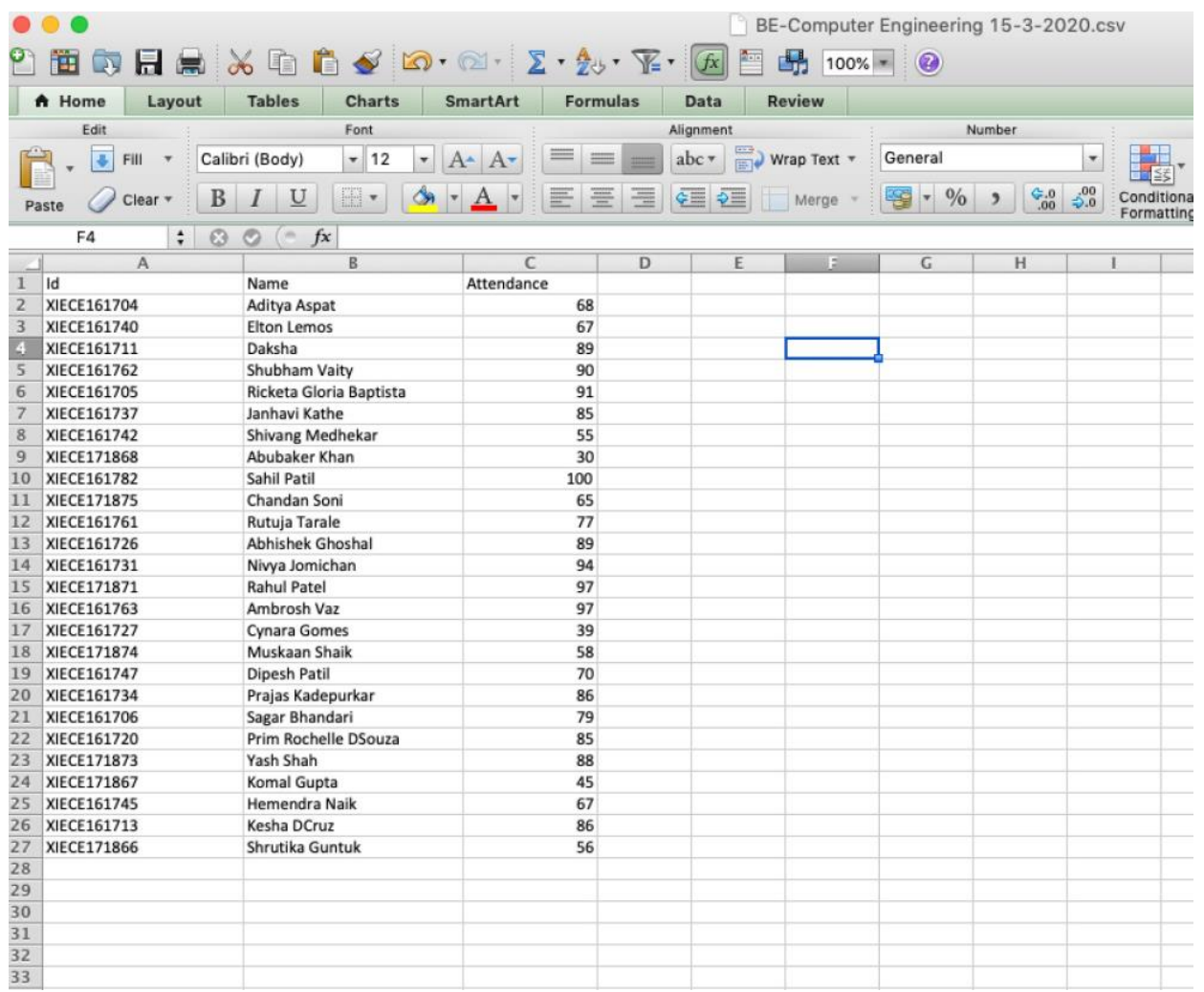

Figure 12. CSV attendance file Sample

This results in the cut down of paper usage for keeping the record of attendance for each subject of each academic year as shown below

- Let's consider that there are 10 subjects per year.

- Each class will require 4 attendance sheets per Year.

- Therefore, 10 subjects $\times 4$ sheets $=40$ sheets per year per class.

- For each batch from First year to the Fourth year let's say there are 12 batches in total, this implies that 40 sheets per year per class $\times 12$ such batches $=480$ sheets per year.

Hence, with our current system, there is no wastage of sheets for marking attendance. As for the electricity module, consider the current scenario, without the IoT Based Smart classroom system, let's say that the average college working hour is seven hours and since there is no system to toggle the electricity according to the occurrence of a lecture or any human presence, the following is the estimated electricity consumption: 


\section{International Journal of Applied Sciences and Smart Technologies}

Volume 3, Issue 1, pages 35-54

p-ISSN 2655-8564, e-ISSN 2685-9432

- 4830W in 7 hours (average time considering all the events when there is no one in the class as well).

- So for 10 such classes in a college $4830 \mathrm{~W} \times 10=48300 \mathrm{~W}$ in one day.

- For one month, the electricity consumption will be $1110900 \mathrm{~W}$ i.e. $1110.9 \mathrm{~kW}$ for 10 classes in 1 month.

- The cost of electricity for this month will be Rs. 5165 (per month).

Now, consider the following case where our system is being used in the institution, the cost of electricity for a month will be calculated as follows:

- $2760 \mathrm{~W}$ in 4 hours; since the system automatically switches of the fans and lights of a lecture hall, unnecessary wastage of energy is minimized. Therefore the average time considered for a lecture hall in a day is 4 hours.

- So for 10 such classes in a college $2760 \mathrm{~W} \times 10=27600 \mathrm{~W}$ in one day.

- For one month, the electricity consumption will be $634800 \mathrm{~W}$ i.e. $634.8 \mathrm{~kW}$ for 10 classes in 1 month.

- The cost of electricity for this month will be Rs. 2915 (per month).

Clearly, the energy consumption and the cost reduces drastically for just one month (see Figure 13), therefore our system helps conserve a lot of electricity in the long run with a decrease in the expense.

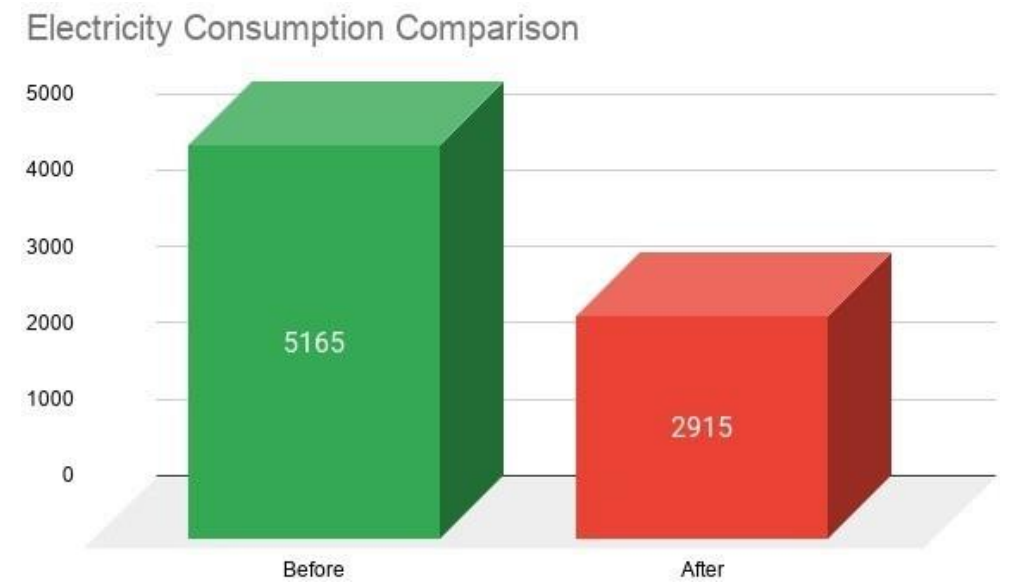

Figure 13. Electricity consumption comparison

\section{Conclusion}

Thus, we have proposed Smart Classroom System, which introduces automated control over electrical components in a classroom for energy saving, and a Portable 


\section{International Journal of Applied Sciences and Smart Technologies}

Volume 3, Issue 1, pages 35-54

p-ISSN 2655-8564, e-ISSN 2685-9432

Electronic Attendance System based on fingerprint identification for efficient use of time and paper, reduce labor work, and even prevent fraudulent attempts to mark the attendance. The initial results are promising but the work is still ongoing as there is a lot of scope for further development. Use of facial recognition to mark the attendance of the students, dividing each lecture hall into sections called grid with motor sensor to detect moving objects in order to toggle the sectional electricity module according to the presence of a person, developing student teacher portal on the app for further usability etc are some of the future scope of this project we are working on.

\section{References}

[1] S. Suresh, H.N.S. Anusha, T. Rajath, P. Soundarya and S.V. P. Vudatha, “Automatic lighting and Control System for Classroom." International Conference on ICT in Business Industry Government (ICTBIG), 1-6, 2016.

[2] C. Wang, X. Li, A. Wang and X. Zhou, "A Classroom Scheduling Service for Smart Classes." IEEE Transactions on Services Computing $X(X), 1-11,2015$.

[3] N. I. Zainal, K. A. Sidek, T. S. Gunawan, H. Manser and M. Kartiwi, "Design and development of portable classroom attendance system based on Arduino and fingerprint biometric." The 5th International Conference on Information and Communication Technology for The Muslim World (ICT4M), 2015.

[4] M. Kassim, H. Mazlan, N. Zaini and M. K. Salleh, "Web based student attendance system using RFID technology." IEEE Control and System Graduate Research Colloquium (ICSGRC 2012), 213-218, 2012.

[5] 2 Channel 5V Relay Module-Wiki, http://wiki.sunfounder.cc/index.php?title=2_Channel_5V_Relay_Module

[6] Interfacing Fingerprint Sensor (R307) with evive - Fingerprint Matching, https://thestempedia.com/tutorials/interfacing-fingerprint-sensor-r307-evivefingerprint-matching/

[7] How to Use an OLED Screen (128 per 64)-Hackster.io, https://www.hackster.io/MisterBotBreak/how-to-use-an-oled-screen-128-per-64cb6e $4 d$ 
International Journal of Applied Sciences and Smart Technologies

Volume 3, Issue 1, pages 35-54

p-ISSN 2655-8564, e-ISSN 2685-9432

This page intentionally left blank 